\title{
Do the selected Trans European transport investments pass the Cost Benefit test?
}

\author{
Stef Proost, Fay Dunkerley, Saskia Van der Loo, Nicole Adler, Johannes Bröcker, Artem Korzhenevych ${ }^{1}$ \\ Stef Proost, Fay Dunkerley, Saskia Van der Loo \\ Center for Economic Studies, Catholic University of Leuven, Belgium. \\ Nicole Adler \\ Hebrew University, Jerusalem. \\ Johannes Bröcker, Artem Korzhenevych \\ University of Kiel, Germany.
}

JEL references: R42, H11, H54,

Keywords: transport infrastructure, cost benefit analysis, Europe Union,

\begin{abstract}
This paper assesses the economic justification for the selection of priority projects defined under the auspices of the Trans-European transport network. In analyzing the current list of 30 priority projects, we apply three different transport models to undertake a cost-benefit comparison. We find that many projects do not pass the cost-benefit test and only a few of the economically justifiable projects would need European subsidies to make them happen. Two remedies are proposed to minimize the inefficiencies in future project selection. The first remedy obliges each member state or group of states to perform a costbenefit analysis (followed by a peer review) and to make the results public prior to ranking priority projects. The second remedy would require federal funding to be available only for projects with important spillovers to other countries, in order to avoid pork barrel behaviour.
\end{abstract}

\footnotetext{
${ }^{1}$ The authors acknowledge the support of the EC - VI th framework program of DG-TREN, FUNDING consortium. Only the authors are responsible for the views that are expressed in this paper. Dunkerley acknowledges the support of the FWO-Flanders project on political economy.
} 


\section{Introduction}

The objective of this paper is to discuss the selection of potential large-scale transport investments based on several modelling approaches. We focus on the trans-European transport networks (TEN-T) that encompass the major planned transport infrastructure in Europe, as depicted in Figure 1. The concept of a transEuropean transport network was formally recognized in the Maastricht Treaty (1992) and the current priority list consists of 30 "priority" projects to be launched before $2010^{2}$. Investment in transport infrastructure does not, however, end with the TEN-T, as the Commission has already proposed the adoption of five trans-national axes ${ }^{3}$, with the purpose of extending the major TEN-T infrastructure to neighbouring countries. European Union interest in the TEN-T has been mainly concerned with the removal of bottlenecks and the completion of missing links to strengthen the internal market ${ }^{4}$. The Van Miert Group ${ }^{5}$, which reported to the Commission on the trans-European network in 2003, defined "European added value” based on a number of selection criteria, including potential socio-economic value. The current priority list consists of projects designated to be of common interest and additionally judged to have overall, net socio-economic benefits. ${ }^{6}$ At present 5 of the 30 priority projects have been completed or are about to be (EC, 2009). Legislative instruments are also in place for the European Commission to subsidize priority projects and provide financial and political support to the member countries to encourage the development of the projects. ${ }^{7}$

In this paper we test this claim, from a purely economic perspective, by performing cost-benefit analyses (CBA) for the priority projects using several transport modelling approaches ranging from a macro to micro scale. In general, a project is worthwhile (or efficient), if it passes a cost-benefit threshold, which is the first step in our analysis. It should be noted that a project may be worthwhile at the European level but not for a specific member country through which the infrastructure crosses. In that case, a European subsidy may be necessary to encourage the member country to invest, leading to an additional step in which the expected welfare benefits of the selected projects on a European scale are evaluated ("European value added"). These judgements may also consider the issues from an equity standpoint, namely whether richer or poorer regions will benefit from a given investment. Since CBA can be performed with different levels of sophistication, we use three complementary models to assess the projects as comprehensively as possible using the data available.

\footnotetext{
${ }^{2}$ Decision 884/2004/EC

${ }^{3}$ Communication of the European Commission COM (2007) 32: Extension of the major trans-European transport axes to the neighbouring countries and regions

${ }^{4}$ See for example Regulation (EC) No 680/2007,

${ }^{5}$ Report of the Van Miert High Level Group on the trans-European network, June 2003.

${ }^{6}$ Decision 884/2004/EC

${ }^{7}$ Regulation (EC) No 680/2007, Decision 2007/60/EC, Decision 884/2004/EC
} 
Based on a reasonable CBA threshold, it appears that the selection of TEN-T priority projects was not efficient. Of the 22 projects assessed in a consistent manner, only 13 pass an elementary efficiency test and only a minority of these have any real "European value added" that may be considered a reasonable justification for E.U. financial aid. One explanation for the apparent poor choice of priority projects is frequently defined as "pork-barrel" politics, which is likely to occur when transportation investments favour a particular constituency, leading to the risk of oversupply when paid for at the federal level . This is consistent with evidence on the allocation of the federal Highway Trust Fund in the US (Knight (2004)). Potential remedies include standardising the CBA procedure under specific, pre-defined rules and limiting European level subsidies only to projects that generate significant benefits (time savings, freight cost savings) accruing to users outside the investing countries.

The paper is organised as follows. In section 2 we discuss the methodologies applied to undertake a costbenefit analysis of the 30 E.U. TEN-T priority projects. In sections 3, 4 and 5 we use three different models to implement the cost-benefit tests from an E.U. wide perspective to a network based approach down to a specific project study. In section 6 we take stock of the results and draw policy conclusions.

\section{Methodology}

\subsection{Cost-benefit analysis as main assessment principle}

Transport investment was one of the first fields in which the methodology of CBA was applied for decision making. Famous examples in the U.K. are the M1 motorway, the Victoria line on the London underground and the third London airport. In France there is a long tradition of "le calcul economique" (Lesourne,1964). According to Bristow and Nellthorp (2000), the methodology of CBA and its application to transport investments has become more or less standard practice in many European countries including the U.K., France, the Netherlands and Germany. These countries have developed manuals (DETR, 2000; OEEI, 1999; BMV, 1993) that are regularly updated. In other countries there is no standard CBA practice and the technique is used for some projects but not for others. At the level of the European Commission there exist manuals defining appropriate rules for CBA. Tsamboulas (2007) argues that a multi-criteria analysis is more appropriate than a CBA for the assessment of multinational transport projects if there is insufficient information, projects interact and values differ across countries. To the contrary, in this paper we argue that the CBA methodology can be applied using a minimum of data per project, given project interaction despite countries demonstrating diverging interests in a project. 


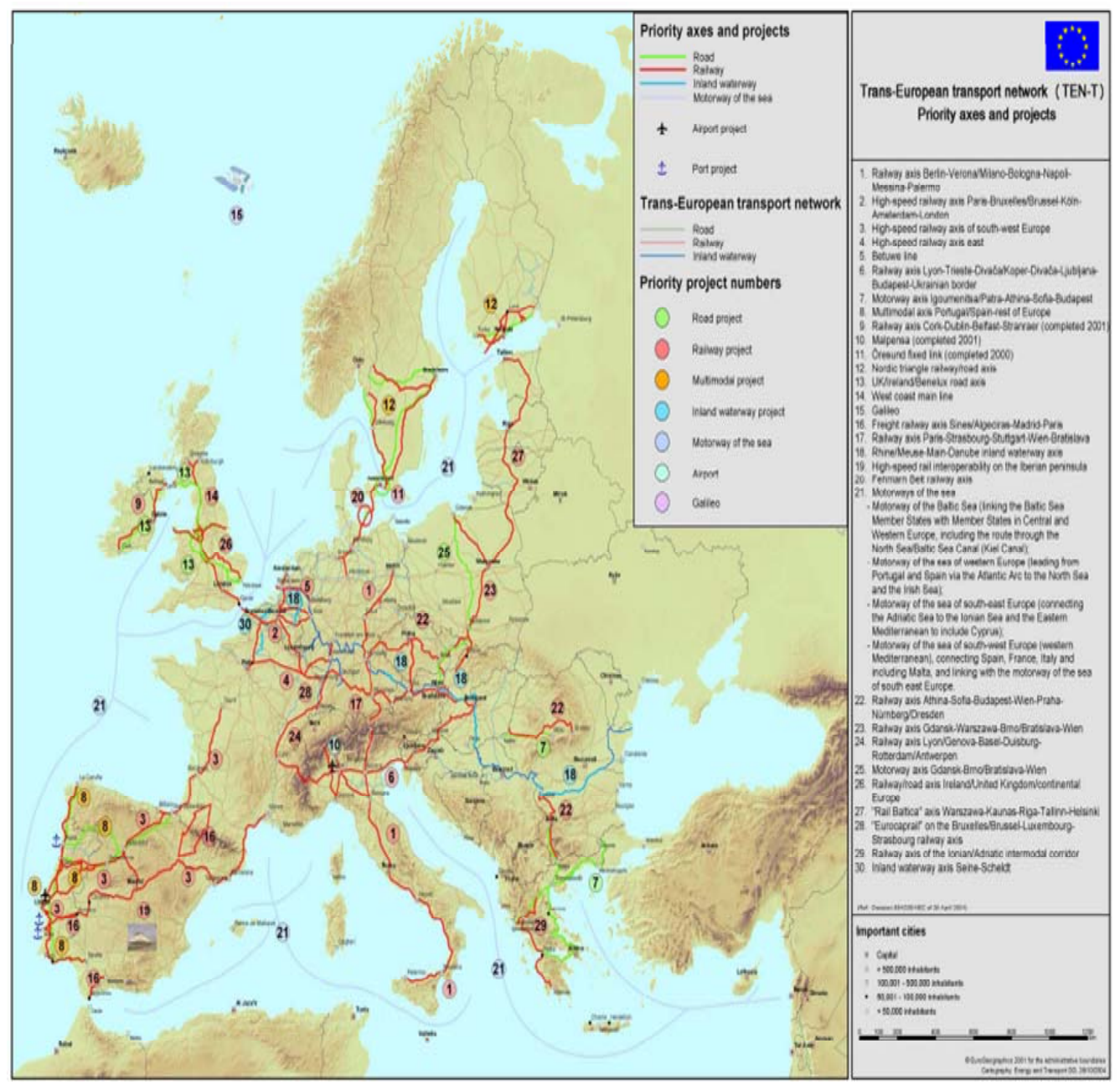

\section{Figure 1: The priority list of TEN-T projects (source: CEC)}

A CBA can be defined as a simplified welfare economic assessment based on a (partial) model of the economy. The choice of the economic model and the welfare function will determine the level of sophistication of the CBA. Beyond the traditional measurement of time and other benefits to users and the fixed project costs, there are three additional levels of sophistication that are sometimes introduced. The first accounts for the side-effects of transport investments that may be considered with regard to alternative transport modes, the environment and the rest of the economy for a given location. This is relevant if there are important market distortions including monopoly margins, taxes and externalities in these markets. For example, a high speed rail investment may divert demand from the aviation sector. If air travellers paid a 
price in excess of the marginal cost, the subsequent decline in air travellers implies a loss of profits for the airline industry. This is a loss that ought to be accounted for in the CBA, as the transfer from air to rail saves fewer real resources than appears in the consumer surplus gain within the rail market (see Kidokoro 2004 for a demonstration of the effects on transport networks). Similarly, if air transport was taxed heavily, the loss of tax revenues from the air transport market is a net welfare loss to be taken into account because the real resource saving of a decease in air transport volume is understated. Consider next the environmental damage associated with air transport. If user prices for air travel equal the social marginal cost and rail is environmentally harmless, any reduction in air transport saves environmental damages and this represents an extra benefit to be accounted for in the social welfare computations. One of the largest market distortions in an economy are labour taxes. If any gap or surplus in the government budget generated by the project is paid for through supplementary labour taxes, this may justify a "marginal cost of funds” premium for projects that generate additional public revenue. The effects on public revenues appear via changes in subsidised transport markets but can also be drawn from higher labour participation when commuting times decrease.

The second addition to a CBA considers the income distribution effects of the investment project. Income distribution across income groups or among regions is often used as a political argument to favour specific projects, therefore it may be useful to define them explicitly within the project assessment. For example, specific equity thresholds could be defined within the CBA guidelines. The third dimension considers the effect of the proposed infrastructure on regional growth, including new economic activities attracted to a region as a direct result of the project. This is obviously important with respect to regional distribution. For the first and second levels of sophistication, the techniques are known and not disputed (Calthrop et al., 2010, and Mayeres and Proost, 2001). With regard to the endogenous location of economic activities, the methodology is more difficult to implement, certainly for a specific project (Fujita and Thisse, 2008).

\subsection{Modelling tools}

The most direct approach for assessing the selection of projects would be to analyze the existing costbenefit studies and verify their quality. There have been several transport modelling studies of the TEN-T projects, not all of them focusing on the cost benefit assessment. De Jong et al. (2004) survey some of the international models, such as STEMM and SCENES, used to assess these projects. Despite the presence of several modeling frameworks for European transport projects, no CBA was available for the vast majority of European TEN-T projects, despite repeated and direct requests to the E.U. Commission. This led us to generate alternative approaches based on the data available. Since no individual model could answer all relevant questions, we developed three different models in an attempt to produce CBA's based on available data. The three types of models used are presented in Table 1 and greater detail is provided in the subsequent sections. 


\section{Table 1: Role of model approaches to assess TEN-T priority projects}

\section{Characteristics \\ Methodology \\ Technical level (portability) \\ Transport effects}

Pricing variants

Economic
assessment
Infrastructure
financial
assessment
Results

\author{
Continent-wide model \\ Model of interregional \\ trade and regional \\ activity in Europe \\ General equilibrium \\ model \\ High level of \\ sophistication, not \\ portable \\ Aggregate level \\ Focus on freight
}
Endogenous pricing of traded commodities, transport pricing is exogenous

Aggregate with focus on freight transport No

Checking regional implications of a large investment project

\section{Network-based model \\ Model for E.U. long- distance passenger transport market \\ Partial equilibrium game-theoretic model High level of sophistication, reasonably portable Detailed for network considered Focus on passengers Endogenous Nash pricing by transport operators, exogenous infrastructure access charges}

Reasonably detailed

No - possible ex-post

Assessing HSR \& airline competition (investment, pricing, regulation)
Project-based model Model for any case study that can be represented as a small network

Partial equilibrium simulation model

Medium, in principle portable

Limited to case study Focus on freight and passengers

Endogenous Nash pricing as well as exogenous pricing principles (marginal social cost pricing, average cost pricing etc.) by transport operators Extensive Yes

Assessing pricing and investment of one specific project

The three selected models each operate at a different scale. The first, continent-wide model (CGEurope, Bröcker et al. (2010)) draws on the field of new economic geography in order to assess E.U. wide effects of investment and pricing strategies of the TEN-Ts. CGEurope has no detailed transport network representation rather considers the potential relocation effects of production. The model analyzes 260 regions that each produce a variety of differentiated goods. The regions are linked via endogenous trade and the effect of transport investments is to decrease the transport costs between specific regions. This model permits endogenous relocation of production activity and trade, tracks regional distribution effects but is too aggregated to look into market distortions in the transport or labour market. The second, networkbased model studies the European long distance passenger transport market where the competition between air and rail promises to be intense (Adler et al. (2010)). This model analyzes the interactions between different transport markets but is a partial equilibrium approach that does not describe income redistribution. The third, project-based model (MOLINO - II, de Palma et al (2010)) is a generic model that can be applied to any project for which some project data are available. The model addresses different types of market distortions and integrates income distribution dimensions.

In summation, the first, generalized model provides a comparable, aggregated assessment of almost all priority projects. The second, network style model tests all the High Speed Rail (HSR) investments on the priority list in greater detail. The third approach represents a more detailed assessment of a particular 
project that allows the importance of pricing and financing variants to be tested. It could only be applied to a few projects, for which more detailed studies were available. In sections 3, 4 and 5 we detail the results of each modelling approach and in section 6, draw on the results of this top down approach, in an attempt to delineate clear public policy guidelines with regard to the funding of infrastructure at a federal level.

\section{Testing European-wide spatial equity and efficiency impacts of the priority TEN-TS}

In order to analyse the spatial impacts of the priority projects for the regions of the European Union with the CGEurope model, each priority project of the trans-European transport projects (TEN-T) is considered individually. The main output of CGEurope is, for each transport investment, the real income effect by region and scenario year. This can then be used to generate a number of measures for testing the efficiency and equity impacts of each project.

The CGEurope model has a household sector and a production sector with two industries, one producing local goods, the other producing tradables under conditions of monopolistic competition. Every region is interested in offering a large variety of goods, including those produced by other regions but this requires freight transport infrastructure. Consequently each region faces a trade-off between diversity and costs. Regions interact through costly trade with trade costs depending, among other things, on the state of the infrastructure. New or upgraded links reduce trade costs, which changes trade flows, production, goods prices and factor prices and thus eventually the welfare of households in different regions. As the model is only able to quantify effects related to trade in goods, a simplified approach is used to add effects stemming from passenger transport. The model is sufficiently simple to allow for a calibration with rather limited information for a large number of regions. It incorporates ideas from New Economic Geography (NEG) (see Fujita et al. 2000) in that it models trade by the popular Dixit-Stiglitz (Dixit and Stiglitz 1977) approach. Another ingredient of NEG models, the endogenous emergence of agglomerations, is however missing in the model due to the assumption of factor immobility.

We report the results of the continent-wide modelling approach in Table 2. Suitable data were available for 22 of the 30 priority projects ${ }^{8}$. Each project is identified by a number and a short description of the route and mode. The third column presents the computed internal rate of return of the project, counting all costs and benefits for the E.U. as a whole. The internal rate of return is the real rate of interest that makes the discounted sum of benefits equal to the investment cost, $C$, of the project. The benefit of the project consists of the real income increase generated by the decrease in production costs and the gain in variety associated with the decrease in freight costs. It is assumed that the user prices cover the operation costs.

\footnotetext{
${ }^{8}$ Projects that had already been completed were not modeled. Further, Galileo, Motorways of the Sea and all Inland Waterway projects were excluded since they were beyond the scope of CGEurope.
} 
The benefit, $B$, is computed for a representative year (2020) and the project's lifetime is assumed to be infinite ${ }^{9}$. The internal rate of return is then the rate $r$ that sets the discounted benefit $B / r=C$. The internal rate of return $r$ is subsequently compared to a benchmark discount rate, $d$, and the former needs to be higher in order for the project benefits to be larger than the opportunity cost of the investment. The third column thus measures the pure efficiency effect of the transport project: total benefits in the E.U. minus total investment costs. The fourth column measures the share of the total E.U. welfare effects that is realized in the countries beyond the country where the investment takes place. When this share is zero, there is no "European value added", as all welfare benefits are localized in the country that makes the investment whereas if it is less than zero, it means that a particular project has negative spillover effects. In the latter case the project decreases welfare in other countries which could arise through the adjustment of the trade and traffic flows. This indicator may be more difficult to compute for projects that are located in and financed by many member states, as the scope for spatial spillovers may then be more limited. In the fifth column we measure the equity effect of the project. In order to compute the equity indicator we need two elements: the distribution of the benefits and the distribution of the costs. The benefits (decreased freight costs that lead to greater variety in consumption) are available per region. For the allocation of the investment costs we need a few rules of thumb. We assume that the project is financed by the investing country and by the other countries in proportion to their share in the benefits. For the non investing countries it is assumed that their share in the investment cost is financed by the E.U. via a proportional E.U.-wide levy tax on GDP. This assumption is a good approximation for levies that take the form of gasoline taxes or of a larger share in V.A.T. receipts. We subsequently evaluate the equity effect of the project by calculating the correlation coefficient between the regional real income gains (in monetary terms) due to project implementation less the corresponding contribution to investment costs, and the relative GDP per capita of the relevant country. A positive correlation coefficient means that richer regions benefit more from the project implementation and the form of finance, while a negative value would mean that poorer regions benefit. Since most TEN-T projects affect many different regions and countries, we would not expect the correlation coefficients to be large in absolute terms.

Technically, the rate of return is high or low if the absolute cost saving is high or low correspondingly. There are two reasons for the estimated cost savings (one of the benefits) from the project to be low: 1) low relative cost change (for example, if there are alternative routes that can be used in a given direction, and capacity constraints are not binding), and 2) low absolute levels of traffic in the benchmark (including transit traffic). For project 5, the Betuwe freight rail line, which shows low levels of efficiency, the first case is relevant, whereas project 29, the intermodal corridor Ioannian Sea/Adria, which also proved problematic, both cases are accurate. For projects 8, 17, 20, 23 and 25, in which the cost-benefit threshold proved reasonable, both the cost changes and the traffic levels are high.

\footnotetext{
${ }^{9}$ In the network-based model, discussed in section 4, the project lifetime was assumed to be 40 years as this was considered more suitable for rail equipment. Compared to an infinite lifetime, a 40 year basis is equal to increasing the annual cost of the investment by $15 \%$.
} 
Drawing on the results presented in Table 2 leads us to three general conclusions. Firstly, based on a benchmark real discount rate of 5\%, only 12 of the 22 projects pass the pure CBA or efficiency test and are deemed worthy of financing. We also tested whether project inter-dependency benefits are of importance because this could help to justify undertaking groups of projects that have, in isolation, a low internal rate of return. However, the continent-wide model found few significant interactions. In general, the newer projects that have been added in the most recent revision of the TEN-T projects, have a higher internal rate of return than the projects on the older list of 20 projects. A few caveats should be noted, as the analysis does not consist of a full CBA for each project. It does not include the variations in external effects such as noise, accidents, pollution, external congestion or any gains for local transport. In addition, the benefits accruing from passenger transport are evaluated in a simplified manner, since these trips are not present in the general equilibrium system (Bröcker et al., 2009). This is especially relevant for the assessment of the high-speed rail projects which mainly impact passenger transport. When we focus on the passenger benefits with the network model in section 4, we find higher net benefits for the HSR projects 1, 3, 6 and 17.

Secondly, we see that in many cases the share of the investing countries in the benefits of the project (column 4 in Table 2) is rather high and the benefits to other countries rather low, which is surprising given the fact that the TEN-T projects were selected under the criterion that they are cross-border and would therefore benefit multiple countries in the E.U. Consequently, the "European value added" of half of the projects is below $10 \%$ and two projects even have a significant negative impact on other countries, namely projects 13 and 26. Only five projects have an internal rate of return over $5 \%$ and offer a reasonable share of benefits to other countries (spillovers), namely projects 8, 17, 20, 23, and 25 could justifiably argue that financial aid from the federal level would make economic sense. Our results confirm sceptical views that have been expressed in the literature (Sichelschmidt, 1999).

Lastly, with respect to the issue of equity, some of the 22 projects mostly benefit the richer countries, while other projects mostly benefit the poorer countries. Hence, neither do we observe a systematic tendency of the selected TEN-T projects to favour lagging regions, nor is the opposite true. Of the four projects identified as being both efficient and providing European value added, three have significantly negative equity coefficients, providing further evidence that federal financing could provide positive results. 
Table 2: Assessment of 22 priority projects using the CGEurope model

Projec

$\mathrm{t} \#$

(1)

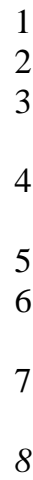

2

3

4

5

6

7

8

12

13

14

16

17

20

22

23

24

25

26

27

28

29
Name of the project

(2)

HSR combined transport North-South

HSR Paris-Cologne-Amsterdam-London

HSR south: Madrid-Barcelon-

Montpellier/Madrid-Dax

High speed rail Paris-Karlsruhe / Luxembourg

/ Saarbruecken

Betuwe line Rotterdam-Rhein/Ruhr

HSR Lyon-Venice-Trieste/Koper-LjubljanaBudapest

Greek motorways (Via Egnatia, Pathe), motorways in Bulgaria and Romania

Multimodal link Portugal-Spain-Central Europe

Nordic triangle

Ireland / UK / Benelux road link

West coast main line

HSR across the Pyrenees, freight line Sines-

Badajoz

HSR combined transport East-West

Fixed link Fehmarn Belt

Rail Athina-Kulata-Sofia-Budapest-ViennaPraha-Nuernberg

Rail Gdansk-Warsaw-Katowice-Brno/Zilinia

Rail Lyon/Geneva-Basel-Duisburg-Rotterdam-

Antwerp

Motorway Gdansk-Katowice-Brno-Vienna

Multi-modal link Ireland/UK/continental

Europe

Rail Baltica

Eurocaprail Brussels-Luxembourg-Strasbourg

Intermodal corridor Ioannian Sea/Adria

\author{
EFFICIENCY: \\ EU-wide yearly \\ rate of return, $r$ \\ $\%$
}

(3)

1.56

2.07

4.48

5.18

0.01

1.38

4.89

6.83

2.04

5.95

1.20

8.18

5.16

9.85

9.98

9.47

2.87

14.82

18.47

16.07

9.10

0.05

\section{EUROPEAN \\ VALUE \\ ADDED \% of \\ total European \\ benefits realized outside the \\ investing}

(4)

3

47

7

4

55

8

19

23

EQUITY:

Correlation \%

between the

regional welfare

effects and

GDP per capita,

(5)

5.13

17.98

6.24

14.69

$-0.12$

4.79

$-15.77$

$-10.71$

20.81

21.96

23.14

$-1.72$

12.00

10.03

$-32.12$

$-29.09$

17.26

$-14.32$

16.36

$-15.87$

14.58

$-8.66$

\section{Do the High Speed Rail extension projects make sense?}

The second, network-based model evaluates the likely equilibrium outcomes on the European long distance passenger network for rail and air travel that results from the competition between one European rail operator and five airlines. A distinction is made between three hub-spoke legacy carriers roughly representing the three global alliances and two low cost, regional airlines. Only one European rail operator is distinguished for three reasons: this maximizes the profitability of the rail project (avoiding the issue of 
double marginalization (Tirole (1988), De Borger, Dunkerley, Proost, 2007); there is de facto institutionalized cooperation across countries (Eurostar, Thalys); and, finally, the objectives of the existing rail operators are unclear as are the legal entities likely to exist by the year 2020. The network analyzed included 71 zones, three of which represented traffic flow to America, Africa and the Far East. All 27 E.U. countries are represented, some more disaggregated than others in order to cover the train network in greater detail, as shown in Figure 2.

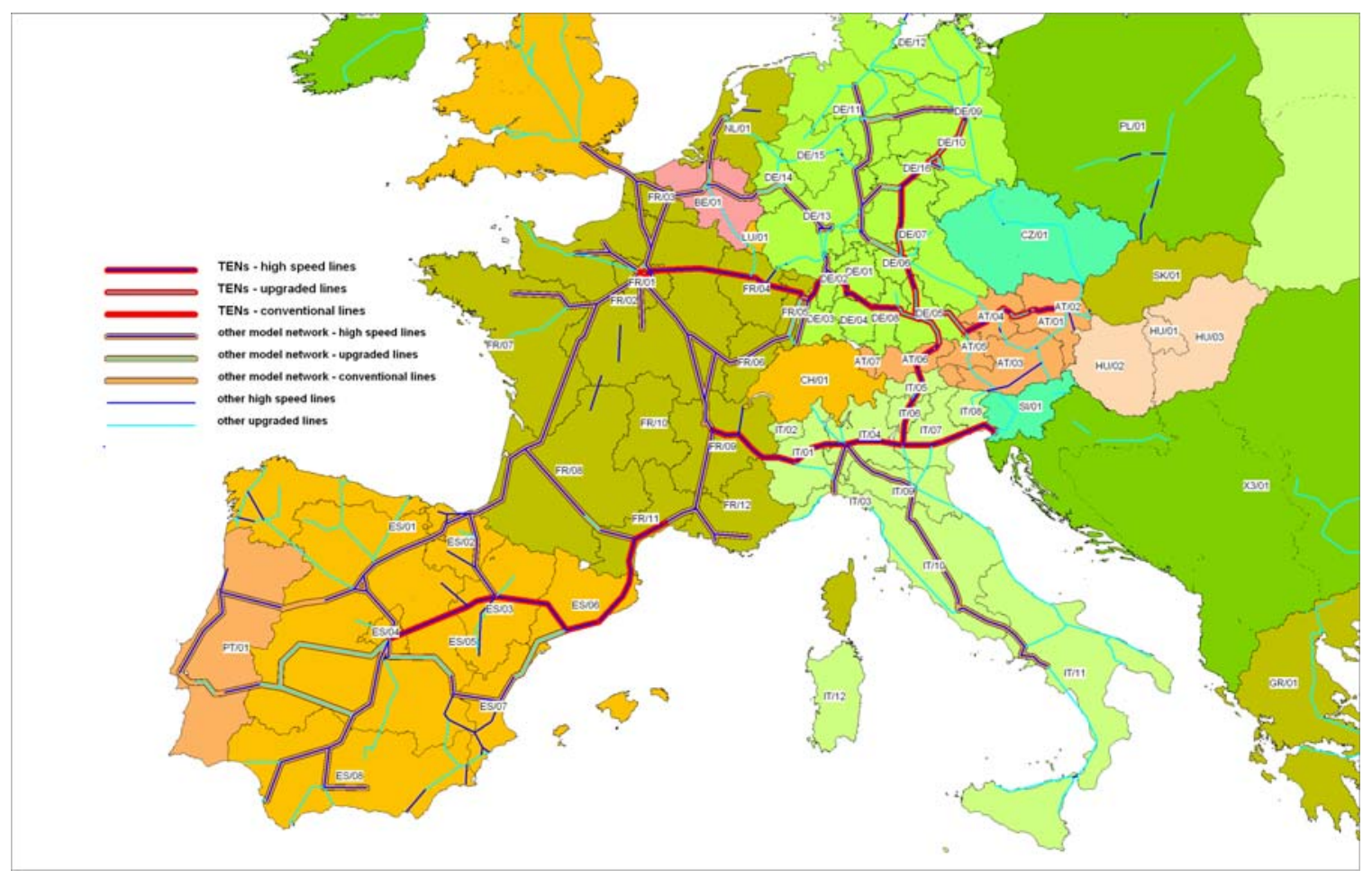

\section{Figure 2: High speed rail TEN-T projects (source CEC)}

Using a game theoretic setting, the network-based model computes equilibria with and without the highspeed rail investments, permitting analyses of the level of rail infrastructure charges on the transport operators' behavior. This is an important issue, since it has been argued that rail infrastructure charges play a major role in determining the competitive position of high speed rail (UIC, 2008) and the ability to utilize the infrastructure efficiently. A social welfare function enables an objective analysis of the potential effects of such changes on producers (privatized companies providing transportation services), consumers (the traveling public, split into business and leisure categories), government authorities (local and federal) and the infrastructure manager, accounting for the effects of infrastructure modifications on taxes and subsidies as well as the environment. The passengers' choice among alternatives is based on the discrete choice theory of product differentiation (Anderson et al., 1996). A representative consumer is assumed for each traveler class (business, leisure) to choose the travel alternative (mode and route) which yields the highest 
utility. The utility depends on the various characteristics of the alternative, including fare, travel time, distance, routing etc. The no-travel / road option is also included such that demand for air and rail can increase or decrease following a change in one of the variables explaining the utility of a passenger. Without this option, such a change would only lead to a redistribution of demand over the various air and rail alternatives.

In equilibrium, the rail and air transport operators maximize profits and compete in prices and frequency of service. The model was solved for different scenarios of the European HSR infrastructure; here the TEN-T investments are the joint implementation of four TEN-T projects $\left(1,3,6\right.$ and 17) ${ }^{10}$. Table 3 summarizes the results as changes compared to two reference scenarios. Both reference scenarios exclude TEN-T HSR investments and the links are assumed to exist but support only conventional rail that runs at a speed of 130 $\mathrm{km} / \mathrm{h}$. In the first reference scenario it is assumed that the HSR operator will be charged an access charge set exogenously at $€ 2 / \mathrm{km}$, which roughly corresponds to marginal cost pricing of the use of the infrastructure. In the second reference scenario it is assumed that the access charges will be based on average cost, set at $€ 10 / \mathrm{km}$ (the values were drawn from GRACE (2005), an E.U. funded project), hence recovering the full infrastructure cost. In computing the cost of the infrastructure, we have assumed a 40year economic life for each of the projects and a 5\% discount rate. The marginal cost of public funds utilized in the social welfare computation was set at 1.2 (Calthrop et al., 2009). In the social welfare computation, the externalities caused by the generation of transport have been monetized according to the mode of transport and include marginal environmental, accident and noise charges (INFRAS/IWW, 2004). The environmental charges have been simplified to a single fixed charge per flight or train trip. The values presented in Table 3 set environmental charges at $€ 100$ per flight and $€ 50$ per train service.

\footnotetext{
${ }^{10}$ Note that in contrast to the previous section, the impact of these projects on business and leisure passenger travel only is analysed in this model and not freight.
} 


\section{Table 3: Welfare assessment of 4 high-speed rail TEN-T projects with the passenger network-based model ( $€ /$ day): changes compared to reference scenario without TEN's}

Infrastructure Charging Case

Rail Access Charge $(€ / \mathrm{km})$

Consumer Surplus

Producer Surplus

Environmental Charge

Air Taxes

Rail Taxes

Government Surplus

Externalities: Europe

Externalities: International

Fixed cost of TENs

Infrastructure Manager Surplus Social Welfare
(1)

\begin{tabular}{rrrr} 
& \multicolumn{2}{c}{10} \\
& $29,597,167$ & & $12,663,677$ \\
& $14,504,893$ & & $-2,155,691$ \\
$1,270,123$ & & 435,565 & \\
$-180,560$ & & $-1,109,331$ & \\
$7,640,220$ & & 0 & $-808,519$ \\
& $10,475,737$ & & $-164,718$ \\
& $-273,788$ & & $-16,015$ \\
& 39,118 & & \\
$13,423,589$ & & $13,423,589$ & $-13,424,487$ \\
& $-13,423,589$ & & $-3,905,753$
\end{tabular}

cost recovery constraint. If the rail infrastructure provider is constrained to break even, he has to charge $10 €$ per train kilometre which forces the train operator to charge prices beyond the marginal social cost. The result is a large loss in consumer and producer surplus and the investment no longer generates a net benefit. If the railway infrastructure provider is not permitted to adopt a two-part tariff pricing scheme that generates revenue while keeping marginal user prices for the train operator close to the marginal cost, the infrastructure will not be utilized efficiently and the government will need to cover the full investment cost. This leads to the risk of attracting oversized investments and overstated project benefits. Of course, if the real infrastructure costs were underestimated, as has proven true in the past (Flyvbjerg et al., 2004), the outcomes may be considerably less favourable. When the high-speed rail operator is charged more than the marginal social costs, we need to consider case (2) and then efficiency (social welfare) decreases. This also implies that the scope for funding the investment via higher markups on the users is limited and that large subsidies are needed to realize the efficiency gains associated with these TEN projects.

HSR projects are often defended on environmental grounds. In our assessment, environmental externalities play only a minor role in the comparison of the alternative scenarios (rows 7 and 8 of table 3), since the higher levels of externalities caused by greater use of air transport are of a magnitude smaller than a quarter of a million $€$ per day. In conclusion, using the more detailed network-based competitive model, which is better suited to take into account the network effects of HSR and the effects on the competing mode (mainly air), we generate both similar and contrasting results to those of the CGEurope model reported in Table 2. The rough way in which the effects on passenger transport are taken into account in the CGEurope calculations can be expected to substantially downsize the consumer surplus and overall social welfare 
computations demonstrated in Table 3. Consequently, whilst the four HSR projects are unlikely to recover majority of the fixed costs of the infrastructure, they do improve both consumer and producer surpluses, dependent on the infrastructure charging policy.

\section{Analysing four TEN-T projects under the project-based model}

The most detailed level of analysis, at a project level (MOLINO-II), is designed to perform CBA and to test the impact of different pricing and investment rules on any transport infrastructure project. In principle, every project may be studied and for the E.U. or an investor in general, it may be easier and more consistent to use the same simple model to assess very different projects. Compared to the network-based model used for the HSR extensions, MOLINO-II has a simpler network, analysing only one project at a time, but allows for a wider range of pricing policies and a financial analysis. Compared to the continentwide model, MOLINO-II does not consider endogenous relocation of production activity levels but takes on board, in a detailed way, all externalities as well as local transport. We will discuss four of the TEN-T projects including the Betuwe line (project 5), the Gdansk-Vienna/Bratislava corridor (projects 23 and 25), the Brenner Tunnel (project 1) and the Seine-Scheldt (project 30) in order to draw additional information that can only be captured in a detailed study.

The core of the model is a representation of the transport market with several alternatives. These alternatives can be different modes or parallel routes for the same mode in a given network context. Each alternative can be used for freight and passenger transport. The demand module for passenger transport features an aggregate nested CES utility function with three levels: choice between transport and consumption of a composite commodity, choice between peak and off-peak periods, and choice between the two transport alternatives. Elasticities of substitution at each level are parametrically given. Passengers can be segmented into classes that differ with respect to their travel preferences, incomes and costs of travel time. The demand module for freight transport is based on an aggregate CES cost function (production levels are given) and also features three levels. The first level encompasses choice between transport and other production inputs (more capital and labour under the form of more warehousing etc), and the second and third levels are the same as for passenger transport. Freight transport can be segmented into different classes (e.g. local and transit traffic). Transport users pay a generalised cost that contains several components: a resource cost (e.g. fuel for a car), taxes levied by central and local governments (e.g. fuel taxes and car taxes), a user fee (toll or rail fare) and a time cost. For a given infrastructure, travel time depends on the ratio of volume to capacity. The core of MOLINO-II is completed with a financial fund module that includes welfare computations composed of external costs and public finance variables. 


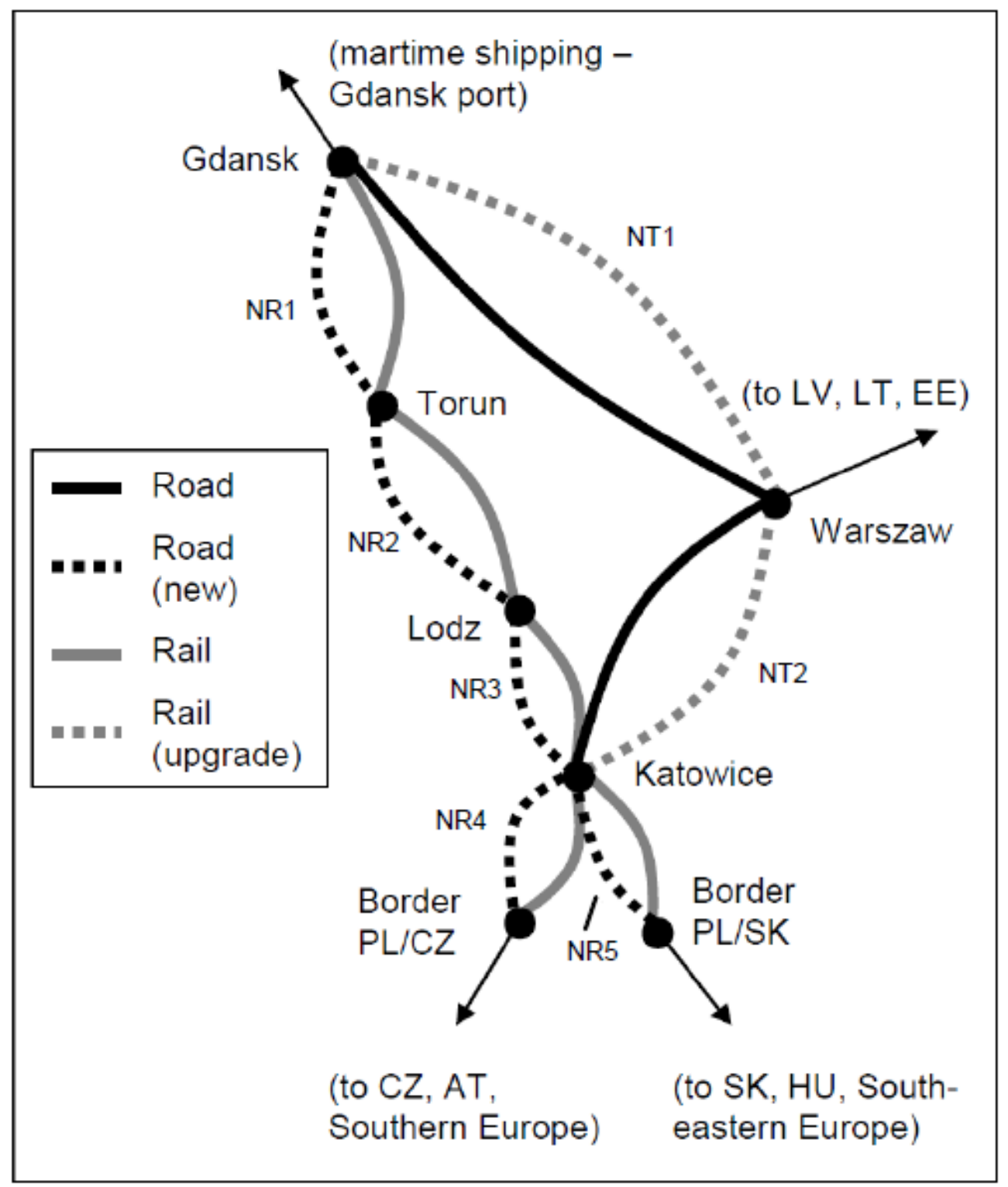

Figure 3: The Gdansk-Vienna corridor in MOLINO format

The Gdansk-Vienna/Bratislava corridor (see FIGURE 3) is a roughly $900 \mathrm{~km}$ long North-South corridor, linking the Baltic Sea port of Gdansk to the Central European capital cities Vienna and Bratislava. Within the TEN-T priority projects, a road project (project 25) and a rail project (project 23) are planned along this corridor. The analysis presented here is limited to the Polish part of the corridor. The overall investment along the entire corridor is estimated at around $€ 7.8$ billion for road development and $€ 5.5$ billion for the rail corridor. Both rail and road projects, as well as their combination, generate welfare gains and this holds true for three pricing regimes: current (lower than marginal cost) pricing, marginal social cost pricing (including road pricing) and average cost pricing for rail. Social marginal cost pricing will 
provide the highest levels of social welfare and would also generate much larger revenues for the rail and road operators compared to other pricing regimes. In terms of economic efficiency, the likely performance of this project appears to be reasonable. Consequently, this infrastructure project appears to be reasonable and can claim national aid but should not require E.U. financial aid.

The Betuwe line is a railway project connecting the port of Rotterdam with the Rhein/Ruhr area. The Dutch part of the rail track was opened for transport in 2007 and cost $€ 4.7$ billion. For the analysis of the Betuwe line, MOLINO was used to assess the effects of different pricing scenarios on the economic and financial viability of this project. One scenario involved full marginal social cost pricing for all transport modes, which performed better than the current pricing approach whereby road use is underpriced. However, the Betuwe line gains only a small market share of the total traffic between the Hamburg-Le Havre range of ports and the German Ruhr area. The net discounted benefits are negative and close to the investment cost. Thus, the project is not justifiable economically and can only survive financially with a subsidy that covers close to $100 \%$ of the initial investment. The project-based model corroborates fully the analysis of the CGEurope model, where this project was deemed inefficient. Unfortunately, the rail line has already been built.

The Brenner tunnel which is an important part of the TEN-T project 1 covering a rail corridor from Berlin to Palermo was also analysed with the project-based model. The tunnel will be dedicated purely to rail transport and is expected to cost at least $€ 4.5$ billion (Proost et al, 2008). Comparing the computed net benefits after nine years of operation with the investment cost of $€ 4.5$ billion, even under the optimal pricing scenario of marginal social cost pricing, will generate net benefits of less than $5 \%$ of the total investment. In economic terms, this is a very weak project and confirms the results for project 1 found in the continent-wide model results presented in Table 2. The major problem is that there is enough rail capacity on the North-South link when all routes in neighbouring Switserland (Gothard, Lötschberg) are taken into account..

The aim of the Seine-Scheldt ${ }^{11}$ project is to connect Belgium and the Netherlands, in particular the ports of Rotterdam and Antwerp to northern France and Paris via inland waterways. The main bottleneck for inland waterway transport in this region is the Canal du Nord between Compiègne and Cambrai. Navigability on this section is at the lower end of international standards, with access restricted to vessels of about 300 tons on some stretches. This canal will be replaced by a new large-gauge canal, which allows barges with a loading capacity up to 4,400 tonnes to pass. Belgium also plans to improve navigability on the axis north of this bottleneck. We concentrate our analysis on the newly constructed canal between Compiegne and Cambrai, as it is the most important investment project planned for this axis. The canal will cost at least

\footnotetext{
${ }^{11}$ Note that this Inland waterways project is priority axis 30 and was not included in the continent-wide analysis.
} 
$€ 2.3$ billion and is planned to be in use in 2012. Again we find low economic efficiency benefits based on the first nine years of operation as the net benefits are of the order of 5 to $10 \%$ of the total investment. There are several reasons for this: the overall freight demand in this corridor is low and there are parallel rail and road options that are not yet saturated. Usually, it is argued that freight traffic on canals should cover only a fraction of the investment costs, since a canal creates additional benefits, including water management, flood protection, accessibility for recreational vessels and recreational facilities on embankments in addition to electric power generation. Traditionally, this lowers the required threshold of net benefits to $50-70 \%$ of the investment, yet this too appears unlikely to be achieved.

\section{Infrastructure policy recommendations}

Our analysis of the selection of projects for the very ambitious TEN-T plan leads to the following four conclusions. Firstly, for most projects that have been selected for E.U. funding, no CBA was made publicly available. Secondly, our analysis of a selection of 22 of the 30 projects, within a consistent top-down CBA framework, shows that only 12 out of 22 projects pass the elementary efficiency test at a discount rate of $5 \%$. Thirdly, only a minority of the selected projects has any real European value added which should be the basis for applying for E.U. financial aid. Lastly, the TEN-T projects are not situated systematically in the poorer regions so it is difficult to defend the selection on pure equity grounds. Further assessment with more detailed models mainly confirms these results but indicate that the TEN-T HSR projects may generate social benefits at the European level. The main source of benefits is not the environmental advantage to air transport but the cost savings and the consumer surplus. This clearly depends on marginal cost pricing for the use of the infrastructure, and this requires high (country and E.U.) subsidies for the construction.

\subsection{Possible explanations}

The selection of transport projects under the TEN-T process appears to fail a basic cost-benefit style analysis. How could this happen? According to political economy theory, the traditional static commonagency lobbying model (Dixit et al (1997)) suggests that a policy maker is influenced by the voting and lobbying processes. The voting process, defined as a black box, results in policies that maximise a weighted sum of individual utility functions. Lobby groups propose to the government a menu of (truthful) lobbying contributions. The lobbying contributions proposed to the policy maker are a function of the policies under discussion and the closer the proposed policy matches the preferences of the lobby group, the higher the lobbying contributions are likely to be. In addition, different groups compete to influence the policy maker.

Utilizing this framework, let us consider the decision to build a specific road or public transport investment in a remote location that cannot be tolled, which is defined as a specific public good (a particular bridge, tunnel etc.). As Persson (1998) and others pointed out, the supply of specific public goods financed by a 
general tax is a very common way to favour a specific lobby group (known as "pork barrel politics"). The problem is that the benefits derived from such an investment are enjoyed by a small group, while the costs are spread over a large group of taxpayers. This provides the local lobby group with a relatively high payoff which will be higher when the users pay only a small fraction of the average cost.

Knight (2004) used the representative democracy model of Baron and Ferejohn (1987) to analyze the decision making process applied to the Interstate Highway Fund in the U.S.A. in the nineties. In this model, the elected representatives will try to favour their own constituency. When a representative becomes the agenda setter, he will form a winning majority of states by selecting those states that are not costly to please in terms of public works and will use the opportunity to favour his district by selecting an oversupply of federally paid public works in his state. Knight shows that for every dollar that is invested, an additional dollar was wasted leading to the funding of a substantial number of inefficient projects.

The E.U. decision process is rather different from the process in most federal countries. In the E.U., it is the council of all European Ministers of Transport that is pivotal in the selection of transport infrastructure projects. It acts upon a proposal of the administration (European Commission) but has enough power to set the agenda and steer the proposals to some extent. The decision of the Ministers is then approved by the European Parliament, known as a co-decision process. As the decision process changes regularly and involves many stages, it is difficult to advance one simple explanation with respect to the selection of projects. Instead, we give two hypotheses that may advance our understanding of the final project selection.

The first is that investment money needs to be spread out over an adequate number of countries and regions to obtain a sufficient majority in the European Parliament. Let us assume that a project, concentrated in one or two countries involving spillovers to the entire European region, existed. This would be unlikely to be politically acceptable at a European level as the system is built such that opportunities to spend federal money needs to be spread across many countries in order to garner sufficient support in the parliament. Consequently, only a portfolio of projects would pass the majority threshold, irrespective of the individual economic efficiency of each project. In this context, it would appear to be reasonable to assume that European ministers of transport systematically chose projects that favour their home constituencies.

The second hypothesis is that many large transport investments have been accepted on the basis of the general transport policy that advocated a strong expansion of rail passenger and rail freight to address road congestion and environmental objectives including GHG emissions. In the CEC (2001) paper, the objective of E.U. transport policy was defined as the need to approximately double the market share of both passenger and freight rail traffic, which had fallen in 1998 to 6\% (passenger) and 8\% (freight) respectively. The majority of the proposed TEN projects are indeed rail projects while their share in overall transport volume is clearly low. When there are absolute modal shift objectives, there is a clear motivation to accept rail projects with a low economic rate of return even if the CBA includes a correct valuation of savings in environmental costs. 
In conclusion, when transportation investments are of use mostly to a small group, be it in a particular region and/or a specific mode, the risk of oversupply exists when it is financed at federal level. The analysis of the decision making process at the E.U. level is difficult. However, there remains one major difference between the U.S. and E.U. funds, since the latter requires a greater level of matching from the countries involved which may explain why many of these projects, defined in 1995 as priorities, still exist only on paper.

\subsection{Potential institutional remedies}

The discussion so far leads us to the inevitable question as to what instruments can prevent this misallocation of resources? Two powerful ingredients in the mechanism design required to ensure optimal infrastructure planning include the CBA procedure itself and the share of the projects that may be legally funded by federal public money.

Bristow and Nellthorp (2000) find that there is a wide variation of CBA procedures amongst the E.U. members. Ideally, we should test the quality of decision making in the different countries and relate this to the procedures used. We limit ourselves to one country that has built a tradition of CBA and has documented the outcomes, namely the Netherlands. In 2000, the Netherlands introduced a requirement that all CBA for major infrastructure projects be carried out using published guidelines. The results are in principle available to Parliament and therefore to the general public. In addition, the Netherlands determines that a CBA is only credible if it is reviewed by peers, in other words, they instituted the practice of a "second opinion". Annema et al (2007) discussed the effects of this requirement on decision making in practice. They find that of the 13 projects reviewed, decisions on 6 projects are still pending, 3 projects exhibited negative CBAs and two of these three were accepted by the government, although one project was subsequently postponed for budgetary reasons. Of the remaining four, 3 got positive CBA's and were accepted, one project was downsized. For many projects, the requirement of a standardised CBA led to a reformulation or postponement of the project. The reformulation is often a downsizing that permits the

project to become economically efficient. We clearly cannot conclude from the Dutch experience that the obligation of undertaking a CBA following certain guidelines is a guarantee that an economically inefficient project is never accepted, but Annema et al. find a clear impact on public decision making.

A second solution to restricting the common pool problem present in the federal funding of infrastructure would be to intervene only if a project has important spillovers. When there are no important benefit spillovers into other regions, it may be strictly preferable to leave the decision process at the member country level and not intervene in the funding of the investment. In addition, one could require private funding (without state guarantee) to finance a pre-specified minimum percentage of the project. The likely outcome would be that inefficient projects remain on paper, as private investors are generally very careful 
at risking their own money. There are two drawbacks to this procedure. Firstly, efficient projects may be selected but may not be priced correctly, although public control is also no guarantee for instituting reasonable pricing tariffs but the incentives to do so are more likely to be present. Secondly, there may be socially efficient projects that will never be proposed by private operators because the benefits of the project cannot be sufficiently creamed by the operator, in which case there will be a mismatch between private and social economic efficiency.

\section{References}

Adler, N., Nash, C. and Pels, E. (2010) High-speed rail and air transport competition: Game engineering as tool for cost-benefit analysis. Transportation Research Part B, forthcoming.

Anderson, S.P., de Palma, A. and Thisse, J-F. (1996) Discrete Choice Theory of Product Differentiation. MIT Press, Massachusetts.

Annema, J.A., Koopmans, C. and Van Wee, B. (2007) Evaluating transport infrastructure investments: The Dutch experience with a standardized approach. Transport Review, 27(2), 125-150.

Baron, D. and Ferejohn, J. (1987) Bargaining and agenda formation in legislatures. American Economic Review, 77, 303-309.

Bundesminister für Verkehr. (1993) Gesamtwirtschaftliche Bewertung von Verkehrswegeinvestitionen. BMV, Essen.

Bröcker, J., Korhenevych, A. and Schürmann, C. (2010) Assessing spatial equity and efficiency impacts of transport infrastructure projects. Transportation Research Part B, forthcoming.

Calthrop, E., de Borger, B. and Proost S. (2010) Cost-benefit analysis of transport investments in distorted economies. Transportation Research Part B, forthcoming.

CEC. (2001) White paper on European transport policy for 2010: Time to decide. http://ec.europa.eu/transport/strategies/doc/2001_white_paper/lb_com_2001_0370_en.pdf

Department of the Environment, Transport and the Regions. (2000) Guidance on Methodology for MultiModal Studies. DETR, London.

De Borger, B., Dunkerley, F. and Proost, S. (2007) Strategic investment and pricing decisions in a congested transport corridor. Journal of Urban Economics, 62(2), 294-316.

De Jong, G., Gunn, H.F. and Walker, W. (2004) National and international freight transport models: An overview and ideas for further development. Transport Reviews, 24(1), 103-124.

De Palma, A., Proost, S. and Van der Loo S. (2010) Assessing transport investments - towards a multipurpose tool. Transportation Research Part B, forthcoming.

Dixit, A.K. and Stiglitz, J.E. (1977) Monopolistic competition and optimum product diversity. American Economic Review, 67(3), 297-308.

European Commission. (2009) Public private partnerships - delivering for the European Transport Network. Directorate General for Energy and Transport. 
Flyvbjerg, B., Skamris Holm, M. and Buhl, S. (2004) What causes cost overrun in transport infrastructure projects? Transport Reviews, 24(1), 3-18.

Fujita, M., Krugman, P. and Venables, A.J. (2000) The Spatial Economy: Cities, Regions, and International Trade. MIT Press, Massachusetts.

Fujita, M. and Thisse, J-F. (2009) New economic geography: An appraisal on the occasion of Paul Krugman’s 2008 Nobel Prize in economic sciences. Regional Science and Urban Economics, 39(2), 109119.

FUNDING. (2007) Case studies: How do the infrastructure fund scenarios affect existing TEN-T projects? European Commission (DG Transport and Energy) under the Transport RTD of the 6th Framework Programme, Deliverable 5.

GRACE. (2005) Generalisation of Research on Accounts and Cost Estimation. European Commission (DG Transport and Energy) under the Transport RTD of the 6th Framework Programme.

INFRAS/IWW 2004. External Costs of Transport: Update study. Final Report, Zurich/Karlsruhe.

Kidokoro, Y. (2004) Cost-benefit analysis for transport networks: Theory and application. Journal of Transport Economics and Policy, 38, 275-307.

Knight, B. (2004) Parochial interests and the centralized provision of local public goods: Evidence from congressional voting on transportation projects. Journal of Public Economics, 88, 845-866.

Lesourne, J. (1964) Le calcul économique. Dunod, Paris.

Mayeres, I. and Proost, S. (2001) Marginal tax reform, externalities and income distribution. Journal of Public Economics, 79(2), 343-363.

Mayeres, I. and Proost, S. (1997) Optimal tax and public investment rules for congestion type of externalities. Scandinavian Journal of Economics, 99(2), 261-279.

Onderzoeksprogramma Economische Effecten Infrastruktuur. (2000) Appraisal of Infrastructural Projects: Guide for Cost-Benefit Analysis. RWS-AVV, Rotterdam.

Persson, T. (1998) Economic policy and special interest politics. Economic Journal, 108, 310-327.

Sichelschmidt, H. (1999) The EU programme "trans-European networks". Transport Policy, 6(3), 169-181.

Tirole, J. (1988) The Theory of Industrial Organization. MIT Press, England.

Tsamboulas, D.A. (2007) A tool to prioritize multi-national transport infrastructure investments. Transport Policy, 14, 11-26.

Union Internationales des Chemins de Fer. (2008) Infrastructure Charges for High Performance Passenger Services in Europe. UIC, Paris. 
Copyright ( 2010 @ the author(s). Discussion papers are in draft form. This discussion paper is distributed for purposes of comment and discussion only. It may not be reproduced without permission of the copyright holder. Copies of working papers are available from the author. 